\title{
EFFICIENCY AND EMPLOYMENT EFFECTS OF GM MAIZE PRODUCERS IN KWAZULU NATAL
}

\author{
Marnus Gouse \\ Department of Agricultural Economics, Extension and Rural Development \\ University of Pretoria \\ Jenifer Piesse (corresponding author) \\ Department of Management \\ King's College London \\ Email: jenifer.piesse@kcl.ac.uk \\ and University of Stellenbosch, RSA \\ Colin Poulton \\ Centre for Development, Environment \& Policy, \\ School of Oriental \& African Studies, University of London \\ Colin Thirtle \\ Centre for Environmental Policy, Imperial College London \\ and University of Pretoria, RSA
}

\section{Paper presented at the Agricultural Economics Association of South Africa conference: Rethinking Agriculture and Rural Development in Southern Africa, Windhoek, Namibia \\ September 2008}

\begin{abstract}
This study uses data for 2006/7, for the Hlabisa, Dumbe and Simdlangentsha districts in KwaZulu Natal, to investigate the relative efficiencies of conventional, insect resistant (Bt) and herbicide tolerant (RR) maize grown by small farmers. The paper fits a stochastic efficiency frontier using maximum likelihood methods. The results show that both GM technologies have very little impact on efficiency and that the tillage system is an important determinant of efficiency levels. This is despite the fact that farmers using herbicide tolerant seed have yields that were $85 \%$ higher. The cost of the seed cancels out this gain in the efficiency estimates and there is every reason to believe that these are the best farmers. The employment effects of the GM technologies are also investigated, as the RR technology is intended to be labour saving and used in conjunction with the minimum tillage method, locally known as planting without ploughing.
\end{abstract}

JEL Classification: O33, Q16.

Key words: KwaZulu-Natal, GM maize, Stochastic Frontiers, Efficiency

Acknowledgements: We thank all of the enumerators, Cebisile, Gloria, Hlengiwe, Isaac, Bongiwe, Ntombfuthi, Zethu, Nkosi and Fikile as without them there would be no study to report. We would also like to thank all the farmers that they have visited seven times each season. This work was undertaken as part of an ERC/DfID project number RES-167-25-0187. The authors are grateful for this financial support. Last, we thank the Rockefeller Foundation who have funded our surveys since 2000 . 


\title{
EFFICIENCY AND EMPLOYMENT EFFECTS OF GM MAIZE PRODUCERS IN KWAZULU NATAL
}

\begin{abstract}
This study uses data for 2006/7, for the Hlabisa, Dumbe and Simdlangentsha districts in KwaZulu Natal, to investigate the relative efficiencies of conventional, insect resistant (Bt) and herbicide tolerant (RR) maize grown by small farmers. The paper fits a stochastic efficiency frontier using maximum likelihood methods. The results show that both GM technologies have very little impact on efficiency and that the tillage system is an important determinant of efficiency levels. This is despite the fact that farmers using herbicide tolerant seed have yields that were $85 \%$ higher. The cost of the seed cancels out this gain in the efficiency estimates and there is every reason to believe that these are the best farmers. The employment effects of the GM technologies are also investigated, as the RR technology is intended to be labour saving and used in conjunction with the minimum tillage method, locally known as planting without ploughing.
\end{abstract}

\section{Introduction}

The rise in world food prices has raised interest in long run food security, including the need for productivity growth to alleviate poverty. IFPRI and IFAD agree that genetically modified (GM) crop varieties are central to increasing food production in SSA, but to date little research has been done on whether GM can produce a Green Revolution (GR) in Africa and if the technology is actually poverty reducing.

The distributional impact of biased technological change depends both on the factor saving (or using) biases and the factor endowments in the economy. If a labour saving technology is introduced in a land scarce/labour abundant economy labour incomes will fall and poverty will increase. GM white maize, developed in the US, is now being used by Zulu smallholders in South Africa (SA). In Asia, importing labour-saving machinery increased 
unemployment and interviews with the few early adopters in SA suggest that GM can reduce planting labour (per unit of output) by about $50 \%$. But the ultimate impact depends on the change in output as well as the bias, and labour for land preparation, planting and weeding is the constraint in much of SSA. If land is poor but plentiful, planting area and output could double and labour demand for all other tasks increase substantially. Thus, a labour saving technology need not displace labour: it depends on the factor endowments and urbanisation and high levels of HIV/AIDS now exacerbates labour scarcity in many communities, including KwaZulu Natal.

This paper is part of a DfID/ESRC project that first investigated the historical effects of factor endowments and biased technological change on labour incomes and poverty using international data (see Thirtle and Piesse, 2008). Then, these surveys will measure the biases of the GM technology and its impacts on labour use, by task, on area planted, output, food prices and household livelihoods. Household modelling techniques will be used to infer the effects in other countries, such as Malawi and Zambia, with different factor endowments. Combining these approaches instead of using standard ex-ante appraisal techniques is an innovation that will allow us to discover the countries or regions in SSA where GM would cause output expansion and those where it should be avoided as labour displacement would be the dominant effect. Thus, we hope to be able to predict the expected poverty impact of GM maize in SSA, which could be an important factor in poverty alleviation.

The next section provides some background on GM maize in South Africa, including summarising the results of past surveys. Section three describes the current samples, with summary statistics and partial productivity measures. Section four gives a very brief review of stochastic frontiers and section five reports the results of fitting a frontier to these sample farms. The final section concludes with a warning that this type of analysis of small samples 
is very dangerous unless the researchers actually know the farmers and the enumerators well enough to scrutinise the results carefully.

\section{Background ${ }^{\mathrm{i}}$}

Bt yellow maize has been produced in South Africa since the 1998/99 season, and large-scale commercial farmers appear to have benefited from its adoption. Despite paying more for seeds, adopters enjoyed increased income over conventional varieties through savings on pesticides and increased yield due to better pest control. Irrigated and dryland commercial farms surveyed in Mpumalanga, Northern Cape, and the North West province enjoyed statistically significant yield increases of $11 \%$ and $10.6 \%$ respectively (at a $95 \%$ confidence level) on average during the 1999/2000 and 2000/01 seasons (Gouse, Pray, Kirsten and Schimmelpfennig, 2005). Planting of GM (Bt and RR) white and yellow maize increased from $14.6 \%$ in 2004/5 (2004 planting season) to above 45\% in 2006/ (Van Der Walt, 2007). 7Much of this increase is due to white maize increasing from $8.6 \%$ of the total white maize area in 2004 to $44.3 \%$ in $2006 / 7$.

\section{Table 1}

Almost all of GM maize production is by commercial farmers, but small amounts are being grown in the communal areas of mainly KwaZulu-Natal, Mpumalanga and the Eastern Cape. Hlabisa is situated just north of the Umfolozi game reserve, which is between Mtubatuba and Ulundi in north-eastern KwaZulu-Natal. The area has an annual average rainfall of more than $980 \mathrm{~mm}$, with $85 \%$ of the rain falling during the production season. Depending on rainfall, planting generally takes place in November and harvesting in June. As much as $75 \%$ of harvested maize grain is kept for household consumption and chicken feed. The low proportion of the marketed surplus is indicative of the level of poverty in the region. 
The majority of households in the area own a small, old hand mill, which produces fairly coarse maize meal.

The Agricultural Research Council and government extension officers have been recommending conservation tillage practises or PWP for some time, due to local erosion problems and Monsanto has also been presenting farmers' days and demonstrations on minimum tillage practises as these form the backbone of a maize production system in which transgenic herbicide tolerant technology is used. . Insect resistant or Bt white maize has been in use since 2001/2, when small quantities of free seed were supplied to small-scale farmers. Surveying 368 farmers in four provinces in 2001/2 and 104 farmers in two northern KZN areas in 2002/3, Gouse, Pray, Schimmelpfennig and Kirsten (2006) found statistically significant yield increases with Bt maize of $32 \%$. The regional results are summarised in Figure 1.In $2002 / 3$ the gain was about halved to $16.8 \%$ and then in $2003 / 4$ the really dry conditions led to no gain at all, as there were almost no stalk borers. Thus, the yield increases are justifiable as it can be directly linked to the stalk borer pressures in the three seasons.

Figure 1

\section{Data}

For the current study, we are collecting data for three areas and the 2006/7 results form the basis of this paper. The sample distribution with respect to districts and seed type is shown in Table 2. There was little GM seed available in the first year, so the survey has been repeated and when these data have been processed, the sample will also include thirty farmers who have adopted the new stacked gene seed that contains both the Bt RR events. For now, only Hlasbisa has anything like adequate sized samples of GM varieties. 
The survey concentrates on accurate measures of output, household characteristics, income, expenses, consumption, farming practices, production budgets and especially on labour use and area planted. The data includes green mealies, which are eaten over the season, before the main harvest. Farmers were surveyed with the help of enumerators who know the area and the farmers, and who had already been trained through their involvement in previous studies. Each respondent was visited seven times during the course of the season. Multiple visits were required to collect reasonably accurate labour data, rather than relying on farmer recall at the end of the season.

\section{Table 2}

The initial visits to each household in October/November/December 2006 entailed the collection of household information, in addition to the labour data and input use for the first maize land preparation and planting activities. During a visit in February, information was collected on pest incidence and on quantities of green mealies harvested, in addition to the ongoing collection of data on labour and input use. Previous studies showed that the MarchMay period is rather quiet, with little maize production activities. The major labour-using periods are during land preparation and planting and the first six weeks after planting for weeding and pesticide application. In May and June, data were collected on the quantities of maize harvested, again in addition to the corresponding labour data.

Table 3 reports the summary statistics of the variables used in estimation. Considerable care was taken to ensure that the data were accurately measured. Output is in kgs of maize, with an average of 380 per farm for the RR users and substantially less for the other farms, despite the fact that RR users have the smallest plots and a wide dispersion. Some farmers had more than one maize plot, in which case only the main focus plot was used in the survey. Land area is in hectares. There are some very small plots and the average maize area is less than half a hectare. Total labour is measured in physical units, in this case, 
days. The land is all marginal (in the sense of having low production potential) and there is little variation in quality or bio-physical characteristics, so there is not a significant quality adjustment problem. The appropriate model is closer to that of Hansen (1979), which assumes unlimited supplies of marginal land, than to the Asian situation where maximizing yield is a main objective.

\section{Table 3}

The intermediate production inputs are seed, fertiliser and power, all measured in Rand. Seed cost is used rather than quantity, to allow for the fact that in some cases Bt seed was over $50 \%$ more expensive than conventional seed. Published prices indicate a $27-30 \%$ price increase due to the technology fee. This is how the RR users have the highest seed costs despite planting the smallest plots on average. Fertiliser varies too, so it is included as a cost rather than a quantity. Here, the conventional seed users are spending less on seed and therefore are able to purchase more fertiliser. As may be expected, the RR users have the highest chemical costs, due to using chemical herbicides to control weeds and the Bt users have the lowest, as their crop is resistant to a major pest. The power costs vary greatly, as the RR users kill the weeds with herbicide and shallow plough with oxen to plant. The last column shows that $40 \%$ of the RR users have their own oxen, whereas for the conventional seed users it is less than $4 \%$. To allow comparable calculations of gross margins, the oxen owners have been imputed a cost of hiring oxen, based on their plot size. For the others, it is the cost of hiring a contractor to plough, which was the option chosen by half the sample, or the running costs for the tractor if one is owned. This under counts the cost, but only seven farmers had a tractor, so imputation was not used. A larger minority prepared the land and planted using hand hoes. 


\section{Production and Labour Use Impacts of Bt, RR and PWP}

\subsection{Effect on Yields and Intermediate Costs}

The impact of the two new technologies on output is considered next and is indeed the main point of the paper. Table 4 reports the output and inputs on a per hectare basis, beginning with yield, or output per hectare, with the area planted measured by our enumerators. This is perhaps the most common measure of the performance of a seed variety and is frequently all that is measured and reported in studies of GM crops. For the full sample, this gives the result that RR outperforms the conventional seed by a factor of $85 \%$ and at this point many studies conclude on a self congratulatory note. Unfortunately, no aspect of reality is ever that simplistic.

The next section of the table shows that this result is due to the 35 RR users in Hlabisa, who actually have very nearly double the yield of conventional seed users in this district. However, whereas $\mathrm{Bt}$ gave a small advantage in yield of $5.9 \%$ more than the conventional seed, in Hlabisa the Bt users had yield that were 7.2\% lower. In Simdlangentsha the Bt users had 9.7\% higher yields and in Dumbe, which had low yields, partly due to stalk borers, the Bt yield advantage was an impressive $47 \%$. Unfortunately, this result is based on only 9 observations, so it may be due to farm and farmer characteristics, rather than the seed itself.

\section{Table 4}

Column two shows that RR is the most expensive seed, followed by $\mathrm{Bt}$, but the differential costs between Bt and RR varies from near zero in Simdlangentsha to 289 Rand in Hlabisa. The reason for this is known and it raises serious doubts as to how the yield results should be interpreted. The $35 \mathrm{RR}$ users in Hlabisa all used the minimum tillage approach, 
locally called planting without ploughing (PWP), that was recommended by the provincial agriculture department. They removed the weeds before planting using an herbicide and then shallow ploughed with oxen to open a furrow for planting. Worse still, due to an increase in the demand for RR seed by commercial farmers and a management/communication/planning blunder by Monsanto, small bags of RR seed was not available for smallholders in 2006/7. A lead farmer in Hlabisa was able to secure a couple of large bags of commercial farmer RR seeds from Monsanto and divided and sold the seed amongst farmers in his area who wanted it. It is important to note that these were smaller seeds for machine planting (compared to larger seeds preferred by smallholders who plant by hand) and cost far more per $\mathrm{kg}$ than the seed Monsanto supplies to smallholders. However, there are of course more seeds per kg. Most maize seed companies in South Africa sell seed to commercial farmers according to the number of seeds in the bag (60 000 or 80000 ) whereas smaller packaging indicates the weight $2 / 5 / 10 \mathrm{~kg}$. Still, it seems our farmer did his sums correctly, as the cost was $76 \%$ higher than the traditional seed, but the yield was $85 \%$ higher.

The position is made worse still by the knowledge of the enumerators, who say that this group of farmers, who all work together, are way above average in their abilities. This is perhaps obvious from the very fact that they managed to obtain RR seed when none was for sale through the normal channels. Thus, it is quite impossible to determine how much of any advantage is attributable to the seeds and how much to the superior innate abilities and farm specific characteristics of this group.

The comparison with the seven RR farmers in Simdlangentsha show how different the two groups are. These farmers did acquire some of the very limited amount of RR seed of the type Monsanto has been selling to smallholders or saved the seed from the previous year. It cost more or less the same as the Bt seed, but still looks like a very poor deal as the average yield was lower than either Bt or conventional seed. All used the tractor services provided by 
contactors, which is an expensive option, rather than PWP and all seem to have done poorly. Either they suffered from lack of prior experience with the new technology, or it is possible that farmers who were able to secure seed did so at the cost of planting at the right time. Worse still again is the comparison with the commercial seed used in Hlabisa, which gave $75 \%$ higher yields on average. Monsanto have claimed to be giving the smallholders seed at reduced prices, but how were the commercial and smallholder seed compared? These two sets of results suggest that the commercial seed is a better deal and well worth the extra price. This issue clearly needs further investigation.

With respect to the Bt seed, the averages for the full sample suggest that in 2006/7 it did not give enough yield advantage to justify its high price. The district results show that in Hlabisa it performed poorly and was clearly a bad investment. In Simdlangentsha, it increased yields enough to justify the higher. However, in Dumbe, the $47 \%$ yield increase came at an extra seed cost of only $25 \%$. Since Bt must save on chemical costs and labour, this looks like a good investment, as indeed Bt is, so long as there is a significant stalk borer infestation. However, contrary to weeds, stalk borer pressure varies from season to season and between areas.

Fertiliser, chemical and power costs at the aggregate level follow the same pattern as in the previous table, as the per hectare basis does not change anything much. However, the district results are enlightening, as they vary considerably. The Bt growers in Hlabisa got poor yields, but this may result from the substantially lower fertiliser applications. The Simdlangentsha farmers did get the best yields with Bt, but at what cost, as they used the heaviest fertiliser applications and somehow spent more on chemicals than the RR users as well as the conventional seed users. The Bt users in Dumbe, by contrast, got their higher yields without recourse to more fertiliser or more chemicals. 
What the Dumbe Bt farmers did instead was save on power, as the last column shows. They actually spent $38 \%$ less on tractors and oxen than the conventional seed users, whereas those in the other two regions spent a little more. It becomes clear that there are too many variables, moving in different directions, to ascertain the impacts of the new seed technologies without aggregating the effects in some way. The obvious approach is to calculate gross margins, so this is done in the next section.

\subsection{Effect on Gross Margins}

The second approach to investigating the impact of GM seeds is usually to calculate gross margins, which are the difference between the value of output and the costs of the intermediate inputs, in this case, seed, fertiliser, chemicals and power. The last of these is the sum of tractor hire costs and oxen hire costs, for those who bought such services. For the half of the sample that owned at least one ox and used their own animals, a cost was imputed using the hire costs and attributing costs according to the land area planted. For the eleven farmers who owned a tractor, the fuel costs were used, which under-counts the real value, but the number is not large enough to affect the results.

The complication is that farmers were selling surplus maize at about Rand 2.40 per kg, but it is far more expensive to buy. The proportion that replaced purchases is not known, so the price was set to make the least profitable group just break even. This was the conventional seed users in Dumbe, who have a zero gross margin at a price of Rand 5.27, so all the other figures are relative to this yardstick. Table 5 shows that for the full sample, RR has an average gross margin that is five times that for conventional seed and more than double

that for Bt. However, this result rests on the group of 35 farmers in Hlabisa, where RR had 2.5 times the margin for conventional and Bt seed. By contrast, for Simdlangentsha, the RR 
users had the worst gross margins and the conventional seed by far the best. Finally, in Dumbe, the Bt users have margins comparable to the Hlabisa farmers, unlike any others in the two less efficient districts.

\section{Table 5}

The frailty and easy misinterpretation that is inherent in small sample surveys such as this is well demonstrated by these results. There are three districts and three winners as a different seed variety proves best in each case.

\subsection{Employment Effects}

The impact of GM crops on employment has attracted little attention to date, but this survey made a point of repeated visits in order to gather accurate labour data. Our experience with labour data based on farmer recall at the end of the season suggests margins of error as big as those for area planted. The data are reported in Table 6, according to task and type of labour used. Table 6 is confined to Hlabisa, where the sample is better balanced, but the other two districts are considered below.

These data require careful analysis and consultation to determine why some of the effects occur, but it does look as if Bt actually saves more labour than RR. ${ }^{\text {ii }}$ Indeed, Bt seems to be twice as labour saving, reducing the input by $28 \%$ relative to conventional seed, whereas RR causes only a $13.7 \%$ cutback. The important proviso here is that all $35 \mathrm{RR}$ farmers were PWP users and this must use more labour, as tractor land preparation and planting is replaced by chemicals and shallow ploughing with oxen (Gouse, Piesse and Thirtle, 2006). This result needs to be compared with that for Simdlangentsha, where tractors were used instead of PWP.

\section{Table 6}

The breakdown of the labour use is intended to give accurate totals, but it was also designed to see what class of labour was affected. For instance, if less child labour is used, 
there could be a benefit in greater school attendance. Here, the picture is just as mixed as in the previous results. Relative to conventional seed, the Bt seems to increase child labour input for all tasks, whereas RR reduces the total. The drop comes from the zero for weeding labour, which is enough to outweigh the need for help from the children to harvest the bigger crop.

Reducing male family labour may allow more employment off the farm, and if this is the case in Hlabisa, it does seem to be male labour that is most reduced. However, Bt reduces female labour almost as much, while RR does not affect it. The common assumption is that this may allow the women to put in more time on tasks like childcare and cooking, which should have benefits for the new generation, apart from improving the lives of the adults by allowing some release from drudgery.

RR clearly reduces hired labour to zero in this sample, but remember that this is a small group who may well not have hired when using conventional seed. Nor does their approach get fully recorded under workgroups, perhaps because their collaborations are fairly continuous and informal. Further study, based on the next years data is badly needed in this important area. There is relatively little hired labour with the conventional seed, but if those who lose this employment are the most resource poor and have insufficient land of their own, these job losses could cause a serious loss of welfare for the most vulnerable.

Table 7 extends the labour analysis to Simdlangentsha and Dumbe, but note there were only seven RR users and three Bt farmers in Simdlangentsha, and only nine Bt farmers in Dumbe. The RR users in Simdlangentsha clearly use less child labour, but there is a $40 \%$ reduction in hired labour, in a district where it was relatively important, so this negative aspect needs checking. The odd results for the Bt users are ignored for now as a sample of three is just to small to justify any discussion.

Finally, there is Bt in Dumbe, which has a very different impact on labour use. Hired 
labour is unaffected, which is good, while family labour is approximately halved, of even more reduced in the case of children. We wait for next years bigger samples before making rash statement on these two districts.

\section{Table 7}

\section{Choice of Model, Functional Form and Results}

The partial productivity measures used above are useful, but like any partial approach, they can be misleading, because they do not present the aggregate or total picture. To deal with this shortcoming, a stochastic frontier model is used, which generates farm level efficiencies that can be compared across technologies. Thus, the effects on land and labour use are also considered, but at the cost of relying on econometric estimation, which may raise more questions than it answers.

\subsection{The Model}

The survey by Battese (1992) shows that fitting frontier production functions to agricultural data has become common. Stochastic frontiers, of the type originally suggested by Aigner, Lovell and Schmidt (1977), discriminate between random errors and farm level differences in efficiency. Battese and Coelli (1995) introduced the inefficiency model, in which the efficiency differences are simultaneously estimated from the stochastic frontier and explained by farmspecific variables. Their models incorporate tests that choose between functional forms and between frontier and mean regression models.

The general form of the production frontier is

$$
\begin{aligned}
& Y_{i}=\alpha+\sum_{j} \beta_{X_{i j}}+\varepsilon_{i} \quad \text { where } \varepsilon_{i}=V_{i}-U_{i} \\
& \text { with } U \sim\left|N\left(0, \sigma_{U}^{2}\right)\right| \text { and } V \sim N\left(0, \sigma_{V}^{2}\right)
\end{aligned}
$$


The $V_{i}$ 's are independently and identically distributed random errors and uncorrelated with the regressors, and the $\mathrm{U}_{i}$ 's are non-negative random variables associated with the technical inefficiency of the farm.

The technical efficiency of an individual farm is defined in terms of the ratio of the observed output to the corresponding frontier output, conditional on the levels of inputs used by that farm. Thus, the technical efficiency of farm $i$ in the context of the stochastic frontier production function is defined as

$$
T E_{i}=\frac{Y_{i}}{Y_{i}^{*}}=\frac{f\left(x_{i}: \beta\right) \exp \left(v_{i}-u_{1}\right)}{f\left(x_{i}: \exp \left(v_{i}\right)\right.}=\exp \left(U_{i}\right)
$$

In Battese and Coelli's (1995) inefficiency model, the $\mathrm{U}_{\mathrm{i}} \mathrm{s}$, in equation (1) are defined as

$$
U_{i}=z_{i} \delta+W_{i}
$$

where $z_{i}$ is a vector of explanatory values associated with farm level technical inefficiencies in production, $\delta$ is a vector of unknown parameters to be estimated and the $\mathrm{W}_{\mathrm{i}} \mathrm{s}$ are the remaining errors. First, the functional form of the stochastic frontier is determined by testing the adequacy of the Cobb Douglas relative to the less restrictive translog. These frontier models are defined as

$$
Y_{i}=\beta_{0}+\sum_{j=1}^{n} \beta_{j} x_{j i}+\sum_{j=1}^{n} \sum_{k=1}^{n} \beta_{j k} X_{j i} x_{k i}+V_{i}-U_{i}
$$

where all of the variables are in logarithms, so that their coefficients are elasticities. If terms under the double summation are not significantly different from zero, the translog reduces to the Cobb Douglas. $\mathrm{Y}$ is maize output in physical terms and the independent variables $\left(\mathrm{x}_{\mathrm{i}}\right)$ are labour, land, seed and fertiliser costs and a dummy for owning oxen. This gives twenty one independent variables in the translog due to the addition of squared and cross product terms.

In equation 4 , in the inefficiency model, there are seven explanatory variables $(z$, in 3$)$, which are dummy variables for Dumbe, sex of the head of household, hired labour and 
intercropping (with pumpkins), plus the number of cattle, the education level of the best educated household member, and surplus labour, which is the number of household members who would like a full time job but can not find work.

\section{$5.2 \quad$ Hypothesis Tests}

First, a series of hypothesis tests were conducted to select the functional form and to choose between the frontier model and the standard average production function. The results are reported in Table 8 . Tests for the preferred functional form, where the null hypothesis $(\mathrm{H} 0)$ is that $\beta_{\mathrm{ij}}=0, \mathrm{i}, \mathrm{j}=1, \ldots, \mathrm{n}$, means that the Cobb-Douglas frontier is an adequate representation for these data. Generalised Likelihood Ratio (LR) tests show that this hypothesis is accepted as the test statistic is below the critical value.

Table 8

The third and last test is that the form of the frontier should be the inefficiency model, rather than including the inefficiency variables in the frontier estimation. The null hypothesis that the $\delta_{\mathrm{i}} \mathrm{s}$ are jointly equal to zero is rejected, meaning the inefficiency model is the correct specification.

\subsection{Results}

The tests establish that the Cobb Douglas function is an adequate representation of the unknown underlying production function, meaning that the cross products and squared terms did not improve the fit sufficiently to justify inclusion. They also show that the frontier is preferred to OLS and that the inefficiency terms have explanatory power. Table 9 reports the parameter estimates and $\mathrm{t}$ statistics for the preferred version of this model, which was selected 
on the basis of LLR tests. The small number of observations for RR and Bt in Simdlangentsha and Dumbe make estimation by district impossible, so only the full sample is used. All the variables are in logarithms (except the dummy for oxen), so the coefficients can be interpreted as elasticities.

Having selected the Cobb Douglas functional form, the next section of Table 8 reports the results of tests of the hypothesis that the technical efficiency effects are not simply random errors. The key parameter is $\gamma=\sigma_{u}{ }^{2} /\left(\sigma_{u}^{2}+\sigma_{v}{ }^{2}\right)$, which is the ratio of the errors in equation (1). So, $\gamma$ is defined between zero and one, where if $\gamma=0$, technical inefficiency is not present, and if $\gamma=1$, there is no random noise. The null hypothesis is thus that $\gamma=0$, indicating that the mean response function (OLS) is an adequate representation of the data, whereas the closer $\gamma$ is to unity, the more likely it is that the frontier model is appropriate. If $\gamma$ is not significantly different from zero, the variance of the inefficiency effects $\left(\mathrm{W}_{\mathrm{i}}\right.$ in equation 3 ) is zero and the model reduces to a mean response function in which the inefficiency variables enter directly (Battese and Coelli, 1995). This test is unambiguous, with the value of 0.717 and the $t$ test indicating that the frontier is the appropriate model. The next column in this section reports the LR test values for the more powerful test with the null hypothesis that $\gamma=\delta_{0}=\delta_{\mathrm{i}}=0$, which means that in addition to $\gamma$ being insignificant, the inefficiency effects are not present in the model. The null hypothesis, $\mathrm{H}_{0}$, can be rejected at the $5 \%$ level, with degrees of freedom equal to the numbers of parameters set to zero. Thus, the frontier model is the correct specification rather than the mean response function.

Table 9

The first part of Table 9 shows that all the output elasticities are significantly different from zero and that they sum to slightly above unity, indicating slight increasing returns to scale. However, the sum is close to unity, so the elasticities should approximate factor shares in output. A one tailed t test is appropriate as the elasticities are constrained by the theory to 
take values between zero and unity. The seed cost variable dominates the others, at 0.415 , meaning that a $1 \%$ increase in seed expenditures increases output by $0.415 \%$. This is large, relative to the elasticities of land and labour, which are normally viewed as the most important inputs in smallholder agriculture. However, it is well below the seed elasticity for the 2004/5 sample, which Gouse, Piesse and Thirtle (2006) estimated at 0.66 . The dummy for owning oxen was included as the power variable because the elasticity for cost of power variable used above in the gross margin analysis was not significant.

The inefficiency variables are far less successful. As these coefficients can be positive (meaning that the variable increases inefficiency) or negative (inefficiency reducing), a two tailed t test is appropriate. Thus, all are insignificantly different from zero in a two tailed test, at the $10 \%$ significance level, except for ownership of oxen. This has a negative sign, which means that it reduces inefficiency. This is a reasonable result as a farmer who owns oxen can ensure that tasks on his or her land can be done in a timely fashion, rather than waiting for a chance to hire the services of another farmer's animals.

Finally, the inefficiencies from the frontier model add a last element of doubt to this study. The results for the full sample, shown in the first row suggest that RR is clearly a superior seed technology, with an almost 10\% yield efficiency advantage over conventional seed. Likewise, Bt seems to reduce efficiency by $2.4 \%$, which is quite possible in a dry year, when stalk borers are not much of a problem. Gouse, Piesse and Thirtle (2006) reached similar conclusions.

\section{Table 10}

Unfortunately, this conveniently simple story does not survive disaggregation to the district level. The gain to RR in Hlabisa is reduced to $0.77 \%$, while in Simdlangentsha using $\mathrm{RR}$ results in a $6.8 \%$ reduction in efficiency relative to conventional seed. Thus, the convenient aggregate results must have rested on the average efficiency of conventional seed 
being dragged down by the Dumbe average of only 0.510 . Likewise, Bt shows a $5 \%$ loss in Hlabisa, but a $2.14 \%$ gain in Simdlangentsha, in efficiency terms. The oddest result is that $\mathrm{Bt}$ appears not to work at all in Dumbe, whereas the gross margin results suggested it was highly successful.

\section{Conclusions}

This study reports and analyses the results of a sample survey of 249 smallholders growing white maize in the districts of Hlabisa, Simdlangentsha and Dumbe, some of whom have adopted either herbicide tolerant or Bt seeds. A particularly large amount of effort was expended on visiting the farmers 7 times in the 2006/7 growing season, with a view to collecting task specific labour data.

The results serve mostly as a warning against putting any faith in the results of studies of GM crops that are based on small samples, especially if the researchers are not well acquainted with the areas and the farmers. Having surveyed some of these farmers since the $2001 / 2$ season, the authors feel reasonably well qualified to judge the veracity of the findings and the verdict is very harsh indeed. A sample of 253, with 249 useable observations seems reasonable, even though there were only 42 Roundup Ready users and 33 using Bt. The analysis shows that this sample is entirely inadequate and that the alternative methods that are used to judge the impact of GM seeds are a further cause of confusion.

A few examples serve to substantiate these claims. The simplest measure of the impact of a new seed variety is yield. The full sample shows that RR has an $85 \%$ yield advantage. Many studies seem to regard yields as sufficient evidence, but how much do yields matter if land is not the constraint? The second approach used is to calculate gross margins and these show that RR has over five times the gross margin of conventional seed. 
The third approach is to take account of land and labour as well, by estimating the individual farm efficiencies relative to a stochastic production frontier. These results show that RR is almost $10 \%$ more efficient than conventional seed.

This consistent story would suit any economist looking for a clear answer and an easy publication. The Bt results fit well too, although they are not unambiguously good. There is a slight yield advantage, which translates into gross margins more than twice those of conventional seed, but the average efficiency level comes out $2.5 \%$ less than that for conventional seed. However, since it has been well documented that the cost of Bt seed is often not justified if it is dry and there are few stalk borer infestations, this is not a bad result to explain.

Now, if this sample of 249 maize plots was all from the same district, there would be no further questions. In fact, the observations are drawn from three districts that are essentially similar. It would be quite possible to have drawn a sample with these distinct differences from a single area. Then the disparities would never come to light, but here, as soon as the results are disaggregated to district level, they fall apart.

The most obvious example is the gross margin rankings. RR ranks top in Hlabisa, conventional seed is top in Simdlangentsha (and RR bottom), while in Dumbe Bt is ranked first. This amounts to three horses winning at three different courses and these results are shown in Table 11, which also shows the rankings for average yields and average efficiency levels.

Of course, all these problems can be avoided by dumping the small gains to be had from adding Simdlangentsha and Dumbe and only considering Hlabisa, but how misleading is Hlabisa in representing the wider region?

Table 11 
Really, the conclusion to this study awaits the more balanced sample based on the data currently being processed for 2007/8, which is shown in Table 1 . However, the within district samples are still small because there are not yet many GM growers, so the inter-district comparisons will still have to be faced. Still, the 2006/7 results mostly serve to show how dangerous it is to make any inferences from small sample surveys.

The positive aspect of this research is that the disaggregated labour data show that neither of the GM crops seems to cause very large reductions in family labour use. The reduction in child labour may mean more schooling, that for women may leave more time for important child rearing tasks and that for men may allow more outside employment. The reduction in hired labour is not large either, so it seems unlikely that GM crops will cause serious employment problems. However, we still have no way of discovering whether less labour use per unit of output will simply mean this diversion of labour to other tasks or whether the area planted can be expected to expand and hence output increase substantially. Is labour a constraint or not? What would cause output expansion in these times of high global food prices? 


\section{REFERENCES}

Aigner D, Lovell K and Schmidt P (1977) Formulation and Estimation of Stochastic Frontier Models, Journal of Econometrics, 6: 21-37.

Battese, G. (1992) Frontier Production Functions and Technical Efficiency: a Survey of Empirical Applications in Agricultural Economics, Agricultural Economics, 7: 185-208.

Battese, G. and Coelli, T. (1995) A Model for Technical Inefficiency Effects in a Stochastic Frontier Production Function for Panel Data, Empirical Economics, 20: 325-332.

Gouse M, Piesse J and Thirtle C, Output and Labour Effects of GM Maize and Minimum Tillage in a Communal Area of KwaZulu Natal, Journal of Development Perspectives, 2:2, December 2006

Gouse, M., Pray, C., Kirsten, J. and Schimmelpfennig, D. (2006) Three seasons of subsistence insect resistant maize in South Africa: Have small-holders benefited. AgBioForum, 9(1): 1522.

Hansen, B. (1979) Colonial Economic Development with Unlimited Supply of Land: A Ricardian Case, Economic Development and Cultural Change, 27: 611-27.

Kodde, D. and Palm, F. (1986) Wald Criteria for Jointly Testing Equality and Inequality Restrictions, Econometrica, 54(5): 1243-48.

Qaim, M and Matuschke, I. (2006) Impacts of Genetically Modified Crops in Developing Countries: A Survey, Quarterly Journal of International Agriculture, 44(3): 207-27.

Thirtle $\mathrm{C}$ and Piesse J, Factor Endowments, Biased Technological Change, Wages and Poverty Reduction: Can Genetically Modified Crops Bring a Green Revolution to SSA? International Journal of Biotechnology, 10 (2/3), 184-206, April 2008. 
Table 1: Percentage and estimated hectares planted to transgenic maize in South Africa

$\begin{array}{llllllll}1999 / 00 & 2000 / 01 & 2001 / 02 & 2002 / 03 & 2003 / 04 & 2004 / 05 & 2005 / 06 & 2006 / 07\end{array}$

\begin{tabular}{lcccccccc} 
Bt Yellow \% & $3 \%$ & $5 \%$ & $14 \%$ & $20 \%$ & $27 \%$ & $22.4 \%$ & $17.8 \%$ & $35.5 \%$ \\
Area & 50000 & 75000 & 160000 & 197000 & 250000 & 249000 & 107000 & 391000 \\
\hline & 0 & 0 & $0.4 \%$ & $2.8 \%$ & $8 \%$ & $8.3 \%$ & $22.8 \%$ & $34.7 \%$ \\
Bt White \% & 0 & 0 & 6000 & 55000 & 175000 & 142000 & 221000 & 552000 \\
Area & 0 & 0 & 0 & 0 & 0 & $1.3 \%$ & $11.3 \%$ & $12.5 \%$ \\
RR Yellow \% & 0 & 0 & 0 & 0 & 0 & 14000 & 68000 & 137000 \\
Area & 0 & 0 & 0 & 0 & 0 & $0.3 \%$ & $6.0 \%$ & $9.6 \%$ \\
RR White \% & 0 & 0 & 0 & 0 & 0 & 5000 & 60000 & 152000 \\
\hline
\end{tabular}


Table 2: Sample farms, by District and Seed Type

\begin{tabular}{lccccc}
\hline \multicolumn{1}{c}{ 2006/07 } & Conventional & Bt & RR & Stacked & Total \\
Simdlangentsha & 59 & 3 & 7 & 0 & 69 \\
Dumbe & 76 & 9 & 0 & 0 & 85 \\
Hlabisa & 39 & 21 & 35 & 0 & 95 \\
Total & 174 & 33 & 42 & 0 & 249 \\
& & & & & \\
2007/08 & & & & 9 & 128 \\
Simdlangentsha & 45 & 29 & 45 & 1 & 104 \\
Dumbe & 66 & 22 & 15 & 20 & 101 \\
Hlabisa & 32 & 11 & 38 & 30 & 333 \\
Total & 143 & 62 & 98 & 30 & 582 \\
Grand total & 317 & 95 & 140 & &
\end{tabular}


Table 3: Data: Averages for Output and Inputs by Seed Type

\begin{tabular}{lcccccccc}
\hline \multicolumn{1}{c}{ Seed Type } & & & \multicolumn{8}{c}{ Seed } & Fertiliser & Chemical & Power & \\
& Output & Area & Labour & Cost & Cost & Cost & Cost & Own Oxen \\
& $\mathrm{kg}$ & ha & Days & Rand & Rand & Rand & Rand & $\%$ \\
Roundup Ready & 380 & 0.317 & 16.6 & 340 & 343 & 629 & 142 & 40 \\
Bt & 280 & 0.416 & 19.8 & 325 & 329 & 250 & 173 & 15 \\
Conventional & 275 & 0.382 & 19.8 & 210 & 511 & 352 & 250 & 3.4 \\
\hline
\end{tabular}


Table 4: Output and Inputs per Hectare for the Full Sample

\begin{tabular}{|c|c|c|c|c|c|}
\hline Seed Type & Output kg & Seed Cost & $\begin{array}{l}\text { Fertiliser } \\
\text { Cost }\end{array}$ & $\begin{array}{l}\text { Chemical } \\
\text { Cost }\end{array}$ & Power Cost \\
\hline \multicolumn{6}{|c|}{ Full sample } \\
\hline \multicolumn{6}{|l|}{ Roundup } \\
\hline Ready & 1386 & 1168 & 1066 & 629 & 454 \\
\hline Bt & 794 & 879 & 917 & 250 & 486 \\
\hline Conventional & 750 & 663 & 1390 & 352 & 810 \\
\hline \multicolumn{6}{|c|}{ Hlabisa } \\
\hline \multicolumn{6}{|l|}{ Roundup } \\
\hline Ready & 1493 & 1237 & 830 & 609 & 452 \\
\hline Bt & 697 & 808 & 584 & 0 & 405 \\
\hline Conventional & 751 & 589 & 721 & 29 & 372 \\
\hline \multicolumn{6}{|c|}{ Simdlangentsha } \\
\hline \multicolumn{6}{|l|}{ Roundup } \\
\hline Ready & 851 & 820 & 2245 & 727 & 463 \\
\hline Bt & 949 & 816 & 2308 & 963 & 539 \\
\hline Conventional & 865 & 470 & 1951 & 686 & 524 \\
\hline \multicolumn{6}{|c|}{ Dumbe } \\
\hline \multicolumn{6}{|l|}{ Roundup } \\
\hline Ready & na & na & na & na & na \\
\hline Bt & 970 & 1067 & 1232 & 590 & 660 \\
\hline Conventional & 660 & 850 & 1299 & 576 & 1072 \\
\hline
\end{tabular}


Table 5: Gross Margins by District and Seed Variety

\begin{tabular}{lcccc}
\hline & Full Sample & Hlabisa & Simdlangentsha & Dumbe \\
RR & 3987 & 4738 & 232 & na \\
Bt & 1653 & 1874 & 376 & 1562 \\
Conventional & 738 & 1886 & 931 & 0 \\
\hline
\end{tabular}


Table 6: Labour Use by Task and Seed Technology in Hlabisa

\begin{tabular}{ccccccc}
\hline & \multicolumn{6}{c}{ Roundup Ready } \\
Child & Male & Female & Hired & Workgroup & All \\
Land Preparation & 1.66 & 6.15 & 9.99 & 0.00 & 0.00 & $\mathbf{1 7 . 8 0}$ \\
Planting & 1.31 & 5.41 & 12.11 & 0.00 & 3.16 & $\mathbf{2 2 . 0 0}$ \\
Herbicide Pre Planting & 0.10 & 1.33 & 1.28 & 0.00 & 0.00 & $\mathbf{2 . 7 2}$ \\
Herbicide Post Planting & 0.00 & 1.24 & 1.14 & 0.00 & 0.00 & $\mathbf{2 . 3 8}$ \\
Weeding & 0.00 & 0.00 & 0.00 & 0.00 & 0.00 & $\mathbf{0 . 0 0}$ \\
Insecticide Application & 0.00 & 0.27 & 0.00 & 0.00 & 0.00 & $\mathbf{0 . 2 7}$ \\
Harvesting & 3.12 & 5.85 & 9.20 & 0.00 & 0.44 & $\mathbf{1 8 . 6 1}$ \\
All & $\mathbf{6 . 1 9}$ & $\mathbf{2 0 . 2 5}$ & $\mathbf{3 3 . 7 3}$ & $\mathbf{0 . 0 0}$ & 3.59 & $\mathbf{6 3 . 7 7}$ \\
& & & & $\mathbf{B t}$ & & \\
Land Preparation & 1.85 & 2.52 & 1.37 & 1.10 & 0.00 & $\mathbf{6 . 8 3}$ \\
Planting & 1.66 & 3.03 & 3.79 & 0.00 & 0.00 & $\mathbf{8 . 4 8}$ \\
Herbicide Pre Planting & 0.00 & 0.00 & 0.00 & 0.00 & 0.00 & $\mathbf{0 . 0 0}$ \\
Herbicide Post Planting & 0.00 & 0.00 & 0.00 & 0.00 & 0.00 & $\mathbf{0 . 0 0}$ \\
Weeding & 3.57 & 6.45 & 13.22 & 0.00 & 1.80 & $\mathbf{2 5 . 0 4}$ \\
Insecticide Application & 0.00 & 0.00 & 0.00 & 0.00 & 0.00 & $\mathbf{0 . 0 0}$ \\
Harvesting & 1.97 & 4.43 & 6.30 & 0.00 & 0.00 & $\mathbf{1 2 . 6 9}$ \\
All & $\mathbf{9 . 0 4}$ & $\mathbf{1 6 . 4 3}$ & $\mathbf{2 4 . 6 7}$ & $\mathbf{1 . 1 0}$ & $\mathbf{1 . 8 0}$ & $\mathbf{5 3 . 0 4}$ \\
& & & Conventional & & \\
Land Preparation & 1.10 & 3.73 & 1.77 & 0.69 & 0.00 & $\mathbf{7 . 2 9}$ \\
Planting & 1.23 & 5.81 & 5.91 & 0.28 & 1.73 & $\mathbf{1 4 . 9 8}$ \\
Herbicide Pre Planting & 0.00 & 0.00 & 0.00 & 0.00 & 0.00 & $\mathbf{0 . 0 0}$ \\
Herbicide Post Planting & 0.00 & 0.00 & 0.00 & 0.00 & 0.00 & $\mathbf{0 . 0 0}$ \\
Weeding & 3.05 & 10.28 & 17.82 & 0.39 & 4.80 & $\mathbf{3 6 . 3 4}$ \\
Insecticide Application & 0.42 & 0.34 & 0.30 & 0.00 & 0.00 & $\mathbf{1 . 0 6}$ \\
Harvesting & 0.53 & 6.17 & 7.53 & 0.00 & 0.00 & $\mathbf{1 4 . 2 3}$ \\
All & $\mathbf{6 . 3 3}$ & $\mathbf{2 6 . 3 3}$ & $\mathbf{3 3 . 3 4}$ & $\mathbf{1 . 3 6}$ & $\mathbf{6 . 5 4}$ & $\mathbf{7 3 . 9 0}$ \\
\hline & & & & & &
\end{tabular}


Table 7: Labour Use by Task and Seed Technology in Simdlangentsha \& Dumbe

\begin{tabular}{|c|c|c|c|c|c|c|}
\hline & \multicolumn{6}{|c|}{ Roundup Ready - Simdlangentsha } \\
\hline & Child & I Male & Female & Hired & Workgroup & All \\
\hline Land Preparation & 0.00 & 1.57 & 0.81 & 1.75 & 0.00 & 4.13 \\
\hline Planting & 0.00 & 3.33 & 5.74 & 4.57 & 5.69 & 19.32 \\
\hline Herbicide Pre Planting & 1.17 & 0.51 & 0.61 & 0.00 & 0.00 & 2.28 \\
\hline Herbicide Post Planting & 2.74 & 0.91 & 2.23 & 0.00 & 0.00 & 5.89 \\
\hline Weeding & 0.00 & 0.00 & 0.00 & 0.00 & 0.00 & 0.00 \\
\hline Insecticide Application & 0.00 & 0.76 & 0.20 & 0.00 & 0.00 & 0.96 \\
\hline Harvesting & 3.04 & 4.97 & 6.60 & 2.84 & 1.62 & 19.08 \\
\hline \multirow[t]{2}{*}{ All } & 6.95 & 12.06 & 16.19 & 9.15 & 7.31 & 51.67 \\
\hline & \multicolumn{6}{|c|}{ Bt - Simdlangentsha } \\
\hline Land Preparation & 0.51 & 3.37 & 4.80 & 1.43 & 0.00 & 10.10 \\
\hline Planting & 3.57 & 10.31 & 7.35 & 7.96 & 12.76 & 41.94 \\
\hline Herbicide Pre Planting & 1.63 & 1.63 & 1.63 & 0.00 & 0.00 & 4.90 \\
\hline Herbicide Post Planting & 1.63 & 2.24 & 1.33 & 0.00 & 0.00 & 5.20 \\
\hline Weeding & 0.00 & 2.45 & 2.45 & 12.24 & 0.00 & 17.14 \\
\hline Insecticide Application & 0.00 & 0.00 & 0.00 & 0.00 & 0.00 & 0.00 \\
\hline Harvesting & 1.94 & 6.22 & 5.51 & 8.57 & 0.00 & 22.24 \\
\hline \multirow[t]{2}{*}{ All } & 9.29 & 26.22 & 23.06 & 30.20 & 12.76 & 101.53 \\
\hline & \multicolumn{6}{|c|}{ Conventional - Simdlangentsha } \\
\hline Land Preparation & 0.74 & 1.76 & 0.93 & 1.46 & 1.48 & 6.37 \\
\hline Planting & 2.63 & 2.62 & 3.57 & 4.57 & 2.86 & 16.25 \\
\hline Herbicide Pre Planting & 1.96 & 0.69 & 1.68 & 0.00 & 0.00 & 4.32 \\
\hline Herbicide Post Planting & 1.86 & 0.65 & 1.58 & 0.00 & 0.00 & 4.09 \\
\hline Weeding & 2.18 & 0.94 & 2.44 & 4.11 & 2.91 & 12.58 \\
\hline Insecticide Application & 0.49 & 0.29 & 0.61 & 0.00 & 0.00 & 1.39 \\
\hline Harvesting & 1.66 & 4.52 & 6.77 & 5.13 & 0.89 & 18.98 \\
\hline \multirow[t]{2}{*}{ All } & 11.52 & 11.47 & 17.58 & 15.27 & 8.14 & 63.98 \\
\hline & \multicolumn{6}{|c|}{ Bt - Dumbe } \\
\hline Land Preparation & 0.92 & 1.86 & 0.31 & 1.17 & 0.00 & 4.26 \\
\hline Planting & 1.38 & 2.53 & 0.82 & 0.54 & 0.00 & 5.26 \\
\hline Herbicide Pre Planting & 0.00 & 0.49 & 0.41 & 0.00 & 0.00 & 0.89 \\
\hline Herbicide Post Planting & 0.00 & 0.49 & 0.05 & 0.00 & 0.00 & 0.54 \\
\hline Weeding & 1.38 & 2.66 & 3.12 & 0.92 & 0.00 & 8.07 \\
\hline Insecticide Application & 0.00 & 0.10 & 0.00 & 0.00 & 0.00 & 0.10 \\
\hline Harvesting & 0.92 & 1.84 & 2.55 & 4.14 & 0.00 & 9.45 \\
\hline \multirow[t]{2}{*}{ All } & 4.60 & 9.96 & 7.25 & 6.77 & 0.00 & 28.58 \\
\hline & \multicolumn{6}{|c|}{ Conventional - Dumbe } \\
\hline Land Preparation & 1.91 & 1.75 & 0.74 & 1.90 & 0.12 & 6.43 \\
\hline Planting & 1.94 & 2.23 & 2.19 & 3.20 & 0.06 & 9.61 \\
\hline Herbicide Pre Planting & 0.01 & 0.27 & 0.12 & 0.00 & 0.00 & 0.40 \\
\hline Herbicide Post Planting & 0.28 & 0.81 & 0.30 & 0.00 & 0.00 & 1.38 \\
\hline Weeding & 4.91 & 6.71 & 11.06 & 1.45 & 0.00 & 24.14 \\
\hline Insecticide Application & 0.23 & 0.17 & 0.25 & 0.00 & 0.00 & 0.64 \\
\hline Harvesting & 0.79 & 3.38 & 3.73 & 0.46 & 0.00 & 8.36 \\
\hline All & 10.07 & 15.33 & 18.38 & 7.01 & 0.19 & 50.98 \\
\hline
\end{tabular}


Table 8: Hypothesis Tests

\begin{tabular}{|c|c|c|c|c|c|c|}
\hline $\begin{array}{c}\text { (1) Functional Form } \\
\text { Test }\end{array}$ & Log-Lil & $\begin{array}{c}\text { elihoods } \\
\mathrm{H}_{1} \text { : }\end{array}$ & LLR Test & DoF & $\begin{array}{l}\chi_{15}^{2} \text { Critical } \\
\text { value at } 5 \%\end{array}$ & Outcome \\
\hline \multirow{4}{*}{$\begin{array}{c}\text { Parameter Restrictions } \\
\mathrm{H}_{0}: \text { All } \beta_{\mathrm{jk}}=0 \\
\text { (2) Frontier Tests }\end{array}$} & $\mathrm{H}_{0}: \mathrm{CD}$ & Translog & Statistic & & & \\
\hline & -237.36 & -226.66 & 21.4 & 15 & 25 & Accept $\mathrm{H}_{0}-\mathrm{CD}$ is adequate \\
\hline & & & LLR test & & \multicolumn{2}{|c|}{ Parameter Restrictions: $\mathrm{H}_{0}: \gamma=\delta_{\mathrm{i}}=0$} \\
\hline & Gamma & t stat & Statistic & DoF & $\begin{array}{l}\text { Critical } \\
\text { Value }\end{array}$ & Outcome \\
\hline $\begin{array}{l}\text { Restrictions: } \\
\mathrm{H}_{0}: \gamma=0\end{array}$ & 0.717 & 7.019 & 35.40 & 8 & 14.85 & $\begin{array}{c}\text { Reject } \mathrm{H}_{0}-\text { frontier not } \\
\text { OLS }\end{array}$ \\
\hline \multirow[t]{2}{*}{ (3) Inefficiency Model } & $\mathrm{H}_{0}: \delta=0$ & $\mathrm{H}_{1}: \delta \neq 0$ & & & & \\
\hline & -252.29 & -237.36 & 29.46 & 7 & 13.40 & $\begin{array}{c}\text { Reject } \mathrm{H}_{0}-\text { the } \delta_{\mathrm{i}} \text { belong in } \\
\text { the frontier }\end{array}$ \\
\hline
\end{tabular}

Notes: The likelihood-ratio (LLR) test statistic, $\lambda=-2\left\{\log \left[\operatorname{Likelihood}\left(\mathrm{H}_{0}\right)\right]-\log \left[\operatorname{Likelihood}\left(\mathrm{H}_{1}\right)\right]\right\}$ is distributed approximately $\chi^{2}{ }_{v}$ where ${ }_{v}$ is the number of parameters assumed to be zero in $\mathrm{H}_{0}$.

Where the null hypothesis involves the parameter $\gamma$, which as a ratio of two variances is necessarily positive, the test statistic has a mixed chi-squared distribution. The critical values are found in Kodde and Palm (1986). 


\begin{tabular}{|c|c|c|c|c|c|c|c|}
\hline $\begin{array}{c}\text { Frontier } \\
\text { Model }\end{array}$ & Labour & Land & Seed & Fertiliser & Chemicals & $\begin{array}{l}\text { Own } \\
\text { Oxen }\end{array}$ & Sum \\
\hline $\begin{array}{l}\text { Coefficients } \\
\text { (full sample) }\end{array}$ & 0.134 & 0.139 & 0.415 & 0.126 & 0.077 & 0.158 & 1.049 \\
\hline t-ratio & 1.613 & $\begin{array}{l}2.663 \\
\text { Sex }\end{array}$ & 5.307 & 2.010 & 3.852 & 1.532 & \\
\hline $\begin{array}{c}\text { Inefficiency } \\
\text { Model }\end{array}$ & $\begin{array}{l}\text { Dumbe } \\
\text { dummy }\end{array}$ & $\begin{array}{l}\text { head } \\
\text { HH }\end{array}$ & $\begin{array}{l}\text { Inter } \\
\text { crop }\end{array}$ & Cows & Education & $\begin{array}{l}\text { Hired } \\
\text { labour }\end{array}$ & $\begin{array}{l}\text { Surplus } \\
\text { Labour }\end{array}$ \\
\hline Coefficient & 1.140 & 0.288 & -0.66 & 3.252 & -0125 & -1.101 & -0.212 \\
\hline t-ratio & 2.971 & 1.214 & -1.11 & 1.592 & -1.300 & -1.650 & -1.142 \\
\hline
\end{tabular}


Table 10: Efficiency Estimates from the Frontier Model

\begin{tabular}{lccccc}
\hline District and Seed & \multicolumn{3}{c}{$\begin{array}{c}\text { Efficiencies by District } \\
\text { and Seed Type }\end{array}$} & \multicolumn{2}{c}{$\begin{array}{c}\text { Gain as \% relative to } \\
\text { conventional seed }\end{array}$} \\
Variety & $\mathrm{RR}$ & $\mathrm{Bt}$ & Conventional & $\mathrm{RR}$ & $\mathrm{Bt}$ \\
All Farms & 0.700 & 0.622 & 0.638 & 9.80 & -2.42 \\
Hlabisa & 0.698 & 0.656 & 0.692 & 0.77 & -5.15 \\
Simdlangentsha & 0.714 & 0.783 & 0.766 & -6.81 & 2.14 \\
Dumbe & $\mathrm{Na}$ & 0.489 & 0.510 & na & -4.06 \\
\hline
\end{tabular}


Table 11: Ranking of Seed Varieties by District and Method

\begin{tabular}{llllllllll}
\hline Method & \multicolumn{3}{l}{ Yields } & \multicolumn{4}{c}{ Gross Margins } & \multicolumn{3}{c}{ Efficiency Levels } \\
District/Rank & $1 \mathrm{st}$ & $2 \mathrm{nd}$ & $3 \mathrm{rd}$ & $1 \mathrm{st}$ & $2 \mathrm{nd}$ & $3 \mathrm{rd}$ & $1 \mathrm{st}$ & 2nd & $3 \mathrm{rd}$ \\
Full Sample & $\mathrm{RR}$ & $\mathrm{Bt}$ & $\mathrm{Con}$ & $\mathrm{RR}$ & $\mathrm{Bt}$ & $\mathrm{Con}$ & $\mathrm{RR}$ & $\mathrm{Con}$ & $\mathrm{Bt}$ \\
Hlabisa & $\mathrm{RR}$ & $\mathrm{Con}$ & $\mathrm{Bt}$ & $\mathrm{RR}$ & $\mathrm{Con}$ & $\mathrm{Bt}$ & $\mathrm{RR}$ & $\mathrm{Con}$ & $\mathrm{Bt}$ \\
Simdlangentsha & $\mathrm{Bt}$ & $\mathrm{Con}$ & $\mathrm{RR}$ & $\mathrm{Con}$ & $\mathrm{Bt}$ & $\mathrm{RR}$ & $\mathrm{Bt}$ & $\mathrm{Con}$ & $\mathrm{RR}$ \\
Dumbe & $\mathrm{Bt}$ & $\mathrm{Con}$ & & $\mathrm{Bt}$ & $\mathrm{Con}$ & & $\mathrm{Con}$ & $\mathrm{Bt}$ & \\
\hline
\end{tabular}


Figure 1: Yields with Conventional and Bt Maize in 2001/2

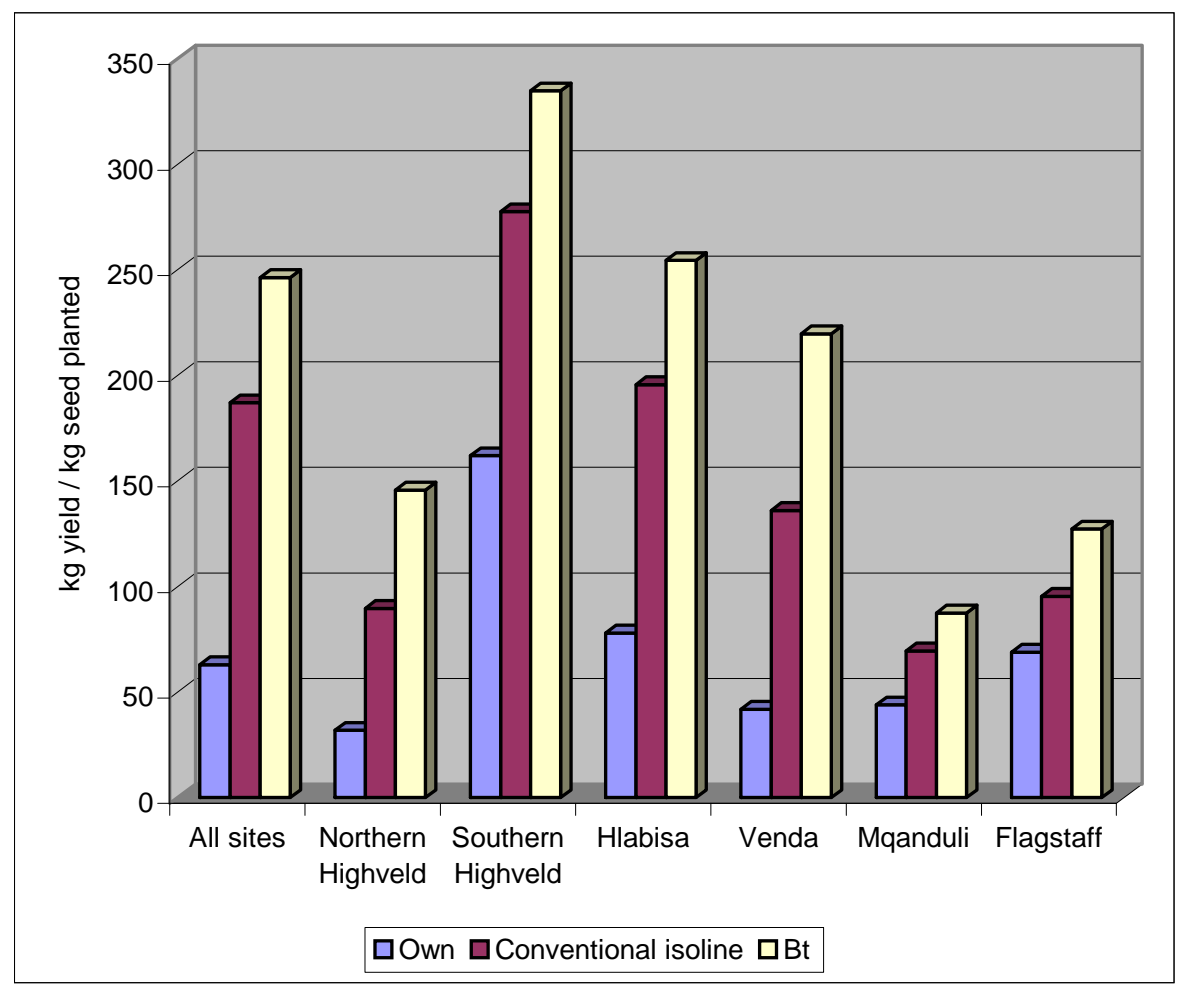




\section{Footnotes}

${ }^{i}$ For a survey of GM crops in developing countries see Qaim and Matuschke (2006). GM maize has been commercially released in Argentina, Honduras, Uruguay and the Philippines, but studies for these countries only followed Bt with RR not being released yet.

ii It is important to note that not all labour activities require the same amount of effort. For example a day of harvesting is not same as a day of weeding 